\title{
The bridges of the future or the future of bridges?
}

\author{
Joan Ramon Casas* \\ Universitat Politecnica de Catalunya - BarcelonaTech, Barcelona, Spain
}

Keywords: construction processes, bridge, transportation infrastructures, modelling, computer tools, sustainability, performance-based design, code-based design

Infrastructures are a key factor for economy. Among them, transportation infrastructures are vital for human life and economy. And within the transportation networks, bridges are key elements for connecting people and delivering goods. For this reason, bridges have been built since many centuries ago, in some way, and the advances (and sometimes geographical expansions!!) of ancient cultures all over the world have been related to their ability of constructing permanent bridges. The most representative of this could be the Roman Empire. After many centuries of bridge construction, nowadays we face a long history of experiences that allow us to look to the evolution of bridge engineering along years and, based on that, to try to extrapolate what is the most feasible to come in the next future. The evolution in bridge engineering has been strongly linked to the key advances in the following areas: materials, construction processes, and modeling. Construction techniques and bridge typologies at the beginning were governed by the mechanical properties and performance of available materials at that time. In fact, when the available materials were stone and masonry (materials that work well in compression but not in tension), the characteristic bridge type was the arch and the construction process, the scaffolding of the complete structure, because the arch action needs the complete structure to develop. For centuries, the arch was the only available bridge type regarding permanent bridges. Of course, suspension and beam configurations were also available but normally with temporary use due to the durability limitations of materials working in tension (vegetal fibers) and bending (timber). Only the appearance in the nineteenth century of new materials as iron and steel, with the ability to resist tensile stresses allowed the birth of permanent suspension and girder bridges. Later on, the combination of a new material, concrete (similar to an artificial stone) and steel, forming reinforced and prestressed concrete made possible for the "new stone" to resist tensile actions and to join segments between them. Something that was not possible with the "old stone"!!. This resulted on an important revolution in the world of bridges. In fact, segmental bridge construction was born, linked to it, and a new group of construction techniques for concrete bridges: balanced cantilever, incremental launching, span-by-span. These new construction processes were also rapidly adopted by the steel bridges. Finally, already in the twentieth century, the use of the computer made affordable the accurate calculation and, therefore, the design and construction of highly redundant bridge types as cable-stayed bridges, and to model very complicate construction sequences. Since then, it seems like bridge engineering related to design and construction of bridges had reached a stationary point and no further relevant advances were envisaged.

Bridge history shows us that for any substantial revolution (or let us say a "before" and an "after") in the field, some relevant fact should occur. There has been a "before" and an "after" in bridge design and construction regarding the come into scene of concrete and steel. Since then, new materials have not appeared. Only recently, fiber reinforced plastics (FRP) were translated into bridge engineering from the aeronautical field. However, these new materials did not lead to relevant changes in bridge typologies or bridge construction schemes, being its main feature, their durability and high strength to weight ratio. There has been also a "before" and an "after" in-bridge construction since the appearance of prestressing. And, finally, there has been 
a "before" and an "after" in bridge design and modeling since the appearance of modeling techniques and affordable computational methods. No relevant advances were seen in construction processes after the development of launching, balanced cantilever, or span-by-span methods. No important advances were seen too in bridge design and structural configurations after the adoption of steel and concrete and the use of computer modeling. As new materials, new construction processes and new modeling techniques are not foreseen in the years to come too, it seems that no "big revolutions" have to be expected in the areas of bridge design and construction.

Most probably just some "small changes" seem feasible, in relation to the following points:

- Introduction of building information modeling (BIM) in the design and execution of large bridge projects.

- Concrete and steel with higher performances (stronger and more durable).

- Small adaptations of existing longitudinal configurations: multi-span suspension bridges (Taizhou bridge in China, Chacao bridge in Chile), partially earth-anchored cable-stayed bridges for spans up to $2000 \mathrm{~m}$.

- Industrialization of the construction process: prefabrication.

- The continuing increase in traffic, particularly freight, giving uncertainty of future degradation rates and enhancing the effects of fatigue.

With today's available materials, construction processes and modeling and computer tools, and the addition of some of the mentioned improvements, it looks feasible to reach all the challenges faced by the bridge engineering community in the years to come regarding the design and construction of new bridges with span-lengths far away from the today's world record signed by the Akashi-Kaykio bridge (main span of $1991 \mathrm{~m}$ ). The span-length range of 2000-3000 m (Storfjord bridge in Norway, Messina bridge in Italy) looks reachable in the next future without key advances in materials, construction processes, and calculation methods.

\section{Conclusion}

The bridges of the future will look more or less alike to the current ones. The future of bridges is on a steady state. No big changes may be expected, no big advances will come!!. Is this true ? Probably yes, if we focus our target into the design and construction areas. These have been the fields where traditionally the main emphasis has been concentrated by the bridge engineering community in the past. This attitude seems logic and natural as the main concern from the society was the construction of new bridges to solve the increasing problems of mobility and connectivity. Probably not at all, if we enlarge our optics. Since short time ago, a new situation asking for a more open focus into the areas of bridge maintenance and service-life aspects has appeared as a result of the following facts:

- In developed countries, a huge stock of bridges exists and it should be properly maintained to guarantee the safety to their users. However, the problem is not only the high quantity of these bridges, but their age. For instance, in the US, a report from ASCE (American Society of Civil Engineers) states that in the year 2013, the National Bridge Inventory (NBI) has registered a total of 607,380 bridges with and average age of 42 years, $11 \%$ of them are considered as structurally deficient. The annual cost of repair and maintenance is in the range of 12 billion of US dollars, although Federal Highway Administration (FWHA)) considers that the optimum expenditure should be twice (ASCE, 2013). In the highway trunk network in Europe, around 1 million bridges exist, with an average age somehow lower than in the US. A total of half a million bridges are estimated in the Europe's railway network, $35 \%$ of them are over 100 years old. With this information, a rough estimate may be obtained of the needs for the next years in the railway bridge stock in Europe. In the next 10 years, some 1500 railway bridges are expected to be strengthened, 4500 have to be replaced, and the deck of other additional 3000 bridges has to be replaced too (MAINLINE, 2014).

- In countries under fast development, the number of existing bridges is still low, but is increasing rapidly. As an example, in China, the total number of bridges has surpassed the United States, ranking first in the world. By the end of 2011, the number of China's highway bridges has reached 689,400 , with a total length of $33,000 \mathrm{~km}$. But an important fact occurs. Although the average age of bridges in China is much smaller than those in the US, the proportion of structurally deficient bridges has already surpassed the US (Zhang et al., 2014). With this actual situation in mind, we may expect an even more dramatic situation in those developing countries in the years to come.

As a consequence, it seems clear that the "big revolution" to come in the future of bridges is more related to the management of the stock of existing (and future) bridge structures. A new lifecycle perspective that equally balances all phases of the bridge life (design, construction, service life and demolition) becomes evident as opposed to the former view mainly oriented to the new construction.

But the new life-cycle approach will not only increase the efforts in the management of existing bridges. It is already feeding new trends in the design and construction areas too. Concepts related to the in-service performance of bridges as robustness (the ability to react to unforeseen actions, not accounted for during the design stage, with a response proportional to the unpredicted action) and resilience (the ability to recover from disasters in an efficient and quick way) have appeared in the design codes and practices because of a major need to design safer and more durable bridges. But also because of the raising concerns on climate change, natural hazards and disasters, and the need of minimizing their effects to bridge assets and to mitigate the threats to urban areas. Consequently, the bridges of the future not only must be safe, economic (at the time of construction and along the whole service life) and durable, but also robust and resilient.

The raising concerns on sustainability and environmentfriendly interventions have also come into the bridge scene. In this sense, the concept of life-cycle assessment (LCA) already used in other engineering fields has appeared in the bridge field as an useful decision-making tool to respond to the need to optimize 
the available economic resources. LCA encompasses not only life-cycle costs (LCC) but also the environment and social costs.

Performance-based design versus code-based design is also a new concept mainly for large design or repair and strengthening bridge projects. The concept is based on an invest-benefit approach and is probably one of the most challenging issues related to bridge design, not for standard bridges, but for large projects, where the constraints imposed by the use of a code of practice (normally calibrated for "normal" situations) should be broken to respond to new design and construction challenges. As new challenging requirements will be arriving to the bridge designers from the society and users in the near future (longer spans, higher actions associated to climate change, longer service-lives, new materials, environmental effects,....), performance-based design will become crucial to solve emerging needs. For those large bridge projects, the trend in their financial needs for construction and maintenance will be increasingly oriented toward a design-build (D-B) basis and public-private partnership (P3). The triangle "performance-based design, D-B project, and public-private partnership" will involve more private funding in the area of bridges, where traditionally public money has been invested by the transportation agencies. And the ability to get private funding will be, again, based on LCA and risk analysis by the private investors. The new P3 approach for bridge funding

\section{References}

ASCE. (2013). "2013 Report card for America's infrastructure," in Bridges: Overview, (American Society of Civil Engineers). Available at: http://www. infrastructurereportcard.org

MAINLINE. (2014). "Maintenance, renewal and improvement of rail transport infrastructure to reduce economic and environmental impacts," in European Project. $7^{\text {th }}$ Framework programme, (European Commission). Available at: http: //www.mainline-project.eu

Zhang, X. G., Liu, G., Ma, J. H., Wu, H. B., and Wu, W. M. (2014). "Design concept and approach on sustainable development of bridge engineering," in Proceedings of IABMAS-2014, Shangai, (London: Taylor and Francis Group). will have a strong influence on the esthetics and conceptual design of bridges too. The $\mathrm{D}-\mathrm{B}$ concept will also evolve to the more general D-B-maintain philosophy. Private investors will place their money on most economical bridges, not only to build, but also to manage. The trend is on the cost-efficient procurement, from a life-cycle perspective, to improve future bridge-investment decisions. Life-cycle cost analysis tools are needed.

As a professor involved in the education of future bridge engineers, I would like to mention the influence of the growing service-life aspects in the education and University curricula. Till now, the need of the society to build new bridges had its echo on the content of bridge engineering courses, only dealing with design and construction issues. However, to respond to the future needs, we have to educate future bridge engineers with new skills, allowing them to face the new challenges related to maintenance aspects, from conceptual design to demolition. Therefore, the content of bridge courses has to balance all aspects of bridge service-life. This will also result on a more self-equilibrated importance between "fundamental subjects" (structural mechanics, strength of materials, ...) and so-called "soft-skills" (economics, sustainability, ...).

In conclusion, the conception of the bridges of the future will be more and more strongly influenced by the future of bridges, i.e., by their service-life performance.
Conflict of Interest Statement: The author declares that the research was conducted in the absence of any commercial or financial relationships that could be construed as a potential conflict of interest.

Copyright (c) 2015 Casas. This is an open-access article distributed under the terms of the Creative Commons Attribution License (CC BY). The use, distribution or reproduction in other forums is permitted, provided the original author(s) or licensor are credited and that the original publication in this journal is cited, in accordance with accepted academic practice. No use, distribution or reproduction is permitted which does not comply with these terms. 